\title{
Towards a true prevalence of peptic ulcer: the Sørreisa gastrointestinal disorder study
}

\author{
B Bernersen, R Johnsen, B Straume, P G Burhol, T G Jenssen, P A Stakkevold
}

\begin{abstract}
This study, designed to overcome methodological problems inherent in earlier prevalence studies of peptic ulcer, was carried out in a municipality in northern Norway. It included the total population of 2027, aged 20-69 years, and comprised a questionnaire and search for previously diagnosed peptic ulcers in the local medical records for all subjects, and additional endoscopy of all subjects with dyspepsia and their matched healthy controls $(n=619)$. The overall prevalence was $\mathbf{1 0 . 5 \%}$ in men and $9.5 \%$ in women, a sex ratio close to one and a higher duodenal:gastric ratio than previously reported from this region. A substantial 1\% prevalence of asymptomatic ulcers was also observed.
\end{abstract}

'Tell me, sweet lord, what is't that takes from thee thy stomach, pleasure, and thy golden sleep?' says Lady Percy to her husband Henry. Not only does classical literature, like Shakespeare's Henry IV, link gastric disorders to men, medical reports also identify peptic ulcer as a male infirmity.

During the past 40 years, studies have consistently shown higher prevalences in men for both gastric and duodenal ulcer. ${ }^{1-3}$ Kurata, however, has reported a decline in sex ratio of self-reported peptic ulcers in the USA to $1: 1 .^{4}$ The prevalence of duodenal ulcer seems to vary considerably around the world, but it generally occurs more frequently than gastric ulcer. ${ }^{1-5}$ Studies in Scandinavia have shown gastric ulcer to be more common than duodenal ulcer in the northern part, ${ }^{6-8}$ whereas duodenal ulcer dominates in the southern part..$^{-11}$ Only one study from Malmø in southern Sweden, which was based on necropsy examinations, showed a higher prevalence of gastric than duodenal ulcer in both men and women. ${ }^{12}$

Studies on the occurrence of peptic ulcer that use patients' records are hampered by considerable biases. Selection takes place both by patients with dyspepsia deciding whether or not to present their problems to the physician and by physicians deciding whether to refer their patients for further diagnostic procedures. Moreover, surveys where the diagnosis of peptic ulcer depends on symptoms are complicated by the fact that some peptic ulcers are asymptomatic. ${ }^{13}$

The purpose of this population based study was to establish an overall prevalence of peptic ulcer, both for symptomatic and for asymptomatic ulcers, by combining a lifetime prevalence from questionnaire reports and examination of available medical records together with a point prevalence from endoscopy of subjects both with and without dyspepsia. The study endeavoured to get closer to the true prevalence of peptic ulcer disease.

\section{Material and methods}

This study was carried out in the municipality of Sørreisa in northern Norway (latitude, $69^{\circ}$ north). The town has $\mathbf{3 5 0 0}$ inhabitants and is in a rural area with a local administration centre. The principal occupations are agriculture and woodprocessing and service industries, a distribution of occupational groups close to the average for Norway. From March to May 1987 all inhabitants born between 1917 and 1967, 2027 men and women, received a postal questionnaire with 119 questions on abdominal complaints, health, lifestyle, diet, and social conditions.

Subjects with positive responses to the first two or the last of the following questions, or both, were considered to have suffered dyspepsia:

Have you ever had abdominal pain of at least two weeks' duration?

If yes, was the pain located to the upper abdomen?

Have you ever had heartburn or acid regurgitation almost daily for at least one week?

Those who had had dyspepsia but no prior history of peptic ulcer, gall stone, kidney stone, cardiac diseases, or abdominal surgery were offered endoscopy. Corresponding asymptomatic controls matched for sex and age (within the same 10 year age group) were randomly selected and offered an endoscopy as well. Controls who refused endoscopy were replaced by a second, similar procedure. Ten pregnant women were excluded from endoscopy, and in the following analysis they were included in the refuser group.

The Figure summarises the study procedures. Of 495 subjects with dyspepsia, 137 were excluded. Of 782 subjects invited to have endoscopy, 309 dyspeptics and 310 controls underwent gastroscopy. The subjects were endoscoped within one month of returning their questionnaires, and after first giving their informed consent.

All endoscopies were performed by one of the authors (BB), who is a trained endoscopist. The examinations were carried out at the local health centre with Olympus gastroscopes GIF Type $Q$ 20. The endoscopist was blinded in the sense of not knowing whether or not he was examining subjects with dyspepsia or controls.

A gastric or a duodenal ulcer was diagnosed if an ulceration greater than $0.5 \mathrm{~cm}$ was seen proximally or distally to the pylorus, respectively. Deformity of the duodenal bulb was considered to be present when flattening, scars, stenosis, or narrowing of the bulb was seen. 


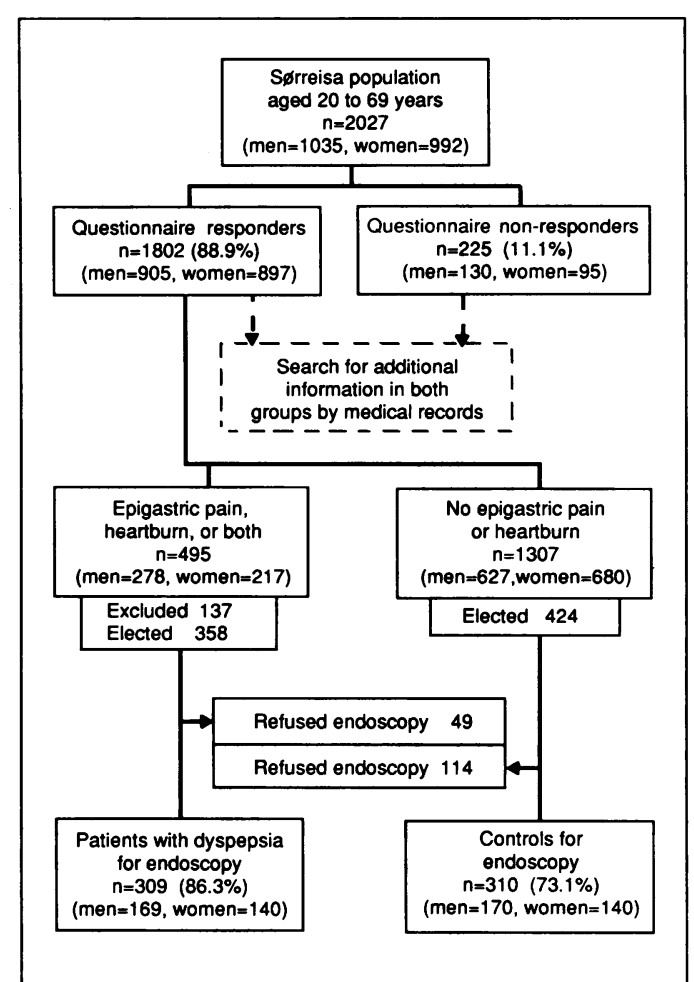

Flowchart of Sørreisa gastrointestinal disorders study

Biopsy specimens were taken from both the greater and lesser curvatures of the corpus and antrum of the stomach, from the proximal and distal parts of the duodenum, and also from all lesions. The specimens for histological examination were prepared and interpreted by the Department of Histopathology at the University Hospital of Tromsø. Finally, the medical records for the total population were examined for evidence of previously diagnosed peptic ulcers confirmed by barium studies or endoscopy.

Table I shows the distribution of the total population and subpopulations by sex and 10 year age groups. Differences in sex and age distribution between the total population and the subpopulations were evaluated by the $\chi^{2}$ test. ${ }^{14}$

Population estimates of point prevalences of peptic ulcer were calculated from the gastroscopic findings adjusted for sex and age by analysis of covariance. ${ }^{15}$ In this calculation the prevalence rates of controls were used for the non-responder group. The overall prevalences in the total population are based on these population estimates and the figures from the record verification procedure.

TABLE I Sex-specific percentage age distribution of total population, questionnaire responders and non-responders, subjects endoscoped and subjects refusing endoscopy (Sørreisa 1987)

\begin{tabular}{|c|c|c|c|c|c|c|c|c|c|c|}
\hline & \multicolumn{2}{|c|}{$\begin{array}{l}\text { Total } \\
\text { population }\end{array}$} & \multicolumn{2}{|c|}{$\begin{array}{l}\text { Questionnaire } \\
\text { responders }\end{array}$} & \multicolumn{2}{|c|}{$\begin{array}{l}\text { Subjects } \\
\text { endoscoped }\end{array}$} & \multicolumn{2}{|c|}{$\begin{array}{l}\text { Questionnaire } \\
\text { non-responders }\end{array}$} & \multicolumn{2}{|c|}{$\begin{array}{l}\text { Subjects refusing } \\
\text { endoscopy }\end{array}$} \\
\hline & Men & Women & Men & Women & Men & Women & Men & Women & Men & Women \\
\hline $\begin{array}{l}\text { No } \\
\text { Age (yrs): }\end{array}$ & 1035 & 992 & 905 & 897 & 339 & 280 & 130 & 95 & 72 & 91 \\
\hline $\begin{array}{l}20-29 \\
30-39 \\
40-49 \\
50-59 \\
60-69\end{array}$ & $\begin{array}{l}27 \cdot 1 \\
22 \cdot 5 \\
21 \cdot 5 \\
14 \cdot 0 \\
14 \cdot 9\end{array}$ & $\begin{array}{l}23 \cdot 8 \\
23 \cdot 9 \\
20 \cdot 5 \\
14 \cdot 1 \\
17 \cdot 7\end{array}$ & $\begin{array}{l}26 \cdot 0 \\
22 \cdot 1 \\
22 \cdot 4 \\
14 \cdot 7 \\
14 \cdot 8\end{array}$ & $\begin{array}{l}21 \cdot 7 \\
24 \cdot 7 \\
21 \cdot 1 \\
14 \cdot 4 \\
18 \cdot 1\end{array}$ & $\begin{array}{r}20.9 \\
26.5 \\
31.6 \\
13.9 \\
7.1 \\
\star \star\end{array}$ & $\begin{array}{l}18 \cdot 9 \\
30 \cdot 0 \\
25 \cdot 4 \\
15 \cdot 7 \\
10 \cdot 0 \\
\star\end{array}$ & $\begin{array}{r}34 \cdot 6 \\
25 \cdot 4 \\
15 \cdot 4 \\
9 \cdot 2 \\
15 \cdot 4\end{array}$ & $\begin{array}{c}43 \cdot 2 \\
15 \cdot 8 \\
14 \cdot 7 \\
11 \cdot 6 \\
14 \cdot 7 \\
\star\end{array}$ & $\begin{array}{r}31 \cdot 9 \\
22 \cdot 2 \\
27 \cdot 8 \\
12 \cdot 5 \\
5 \cdot 6\end{array}$ & $\begin{array}{r}34 \cdot 1 \\
31.9 \\
23 \cdot 1 \\
8.8 \\
2 \cdot 2 \\
\star \star\end{array}$ \\
\hline
\end{tabular}

Significant differences in distribution of age compared with total population by $\chi^{2}$. ${ }^{\star} \mathrm{p}<0.01 ;{ }^{\star \star} \mathrm{p}<0.001$.
TABLE II Sex specific prevalences of self-reported and record verified gastric, duodenal, and peptic ulcer in 1035 men and 992 women aged 20-69 (Sørreisa 1987)

\begin{tabular}{|c|c|c|c|c|c|c|}
\hline & \multicolumn{3}{|c|}{ Men } & \multicolumn{3}{|c|}{ Women } \\
\hline & No & $\%$ & (No) & No & $\%$ & (No) \\
\hline $\begin{array}{l}\text { Reported peptic ulcers } \\
\text { Not confirmed by records } \\
\text { Verified peptic ulcers } \\
\text { False negatives } \\
\text { Ulcers among non- }\end{array}$ & $\begin{array}{r}59 \\
9 \\
50 \\
11\end{array}$ & $\begin{array}{r}6 \cdot 5 \\
15 \cdot 3 \\
1 \cdot 3\end{array}$ & $\begin{array}{r}(905) \\
(59) \\
(905) \\
(846)\end{array}$ & $\begin{array}{r}30 \\
6 \\
24 \\
2\end{array}$ & $\begin{array}{r}3 \cdot 3 \\
20 \cdot 0 \\
0 \cdot 2\end{array}$ & $\begin{array}{r}(897) \\
(30) \\
(897) \\
(867)\end{array}$ \\
\hline $\begin{array}{l}\text { responders } \\
\text { Total peptic ulcers: } \\
\text { Gastric ulcer } \\
\text { Duodenal ulcer } \\
\text { Combined ulcers } \\
\text { Unknown location }\end{array}$ & $\begin{array}{r}3 \\
64 \\
14 \\
45 \\
3 \\
2\end{array}$ & $\begin{array}{l}6.2 \\
1.4 \\
4 \cdot 4\end{array}$ & $\begin{array}{r}(130) \\
(1035)\end{array}$ & $\begin{array}{r}1 \\
27 \\
11 \\
14 \\
2 \\
-\end{array}$ & $\begin{array}{l}2 \cdot 7 \\
1 \cdot 1 \\
1 \cdot 4\end{array}$ & $\begin{array}{r}(95) \\
(992)\end{array}$ \\
\hline
\end{tabular}

Confidence intervals based on the Poisson distribution are given when presenting the prevalences of ulcers in the total population. These intervals indicate the random variation due to the sampling fractions of subjects with and without dyspepsia in the Sørreisa population only. Thus, only the point estimates apply to a universal population.

The study was approved by the local ethical review board.

\section{Results}

Some 1802 of $2027(88.9 \%)$ people returned their questionnaire (Figure). One hundred and thirty seven of 495 subjects with dyspepsia were excluded because of an earlier diagnosis of peptic ulcer in 89 , coronary heart disease in 33 , and gall stones or kidney stones in 15 . Three hundred and nine of the 358 subjects left were eligible for endoscopy, and 309 attended for examination together with 310 of the 424 matched controls. Therefore $79 \cdot 2 \%$ of those invited to endoscopy participated. Of the 163 refusers, 114 were controls.

There were no significant differences in the sex distribution within the populations (Table I). Compared with the total population, middle aged men and women were slightly overrepresented among those undergoing endoscopy. Female non-responders and refusers of endoscopy were significantly younger when compared with the total population. The mean age of subjects with dyspepsia was 40.9 years (range: $20-69$ ) and that of controls was 40.5 years (range: 20-68).

The results from examination of the medical records are presented in Table II. No medical records were found for 103 of the subjects $(5 \cdot 1 \%), 12$ of whom belonged to the endoscoped population without peptic ulcer. Medical records were found for all those who reported a previous peptic ulcer, and they showed a false positive rate of reporting of $15 \cdot 3 \%$ in men and $20.0 \%$ in women. Corresponding false negative rates of reporting were $1.3 \%$ and $0.2 \%$, respectively. When four subjects with peptic ulcers were included among the non-responders, the lifetime prevalences of peptic ulcer were $6.2 \%$ in men and $2.7 \%$ in women, giving a male:female ratio of 2:3:1 and a duodenal:gastric ulcer ratio of $3 \cdot 2: 1$ and $1 \cdot 3: 1$ for men and women respectively.

Table III shows endoscopy results in both subjects with dyspepsia and control subjects. The presented prevalences are adjusted for age 
TABLE III Observed numbers and prevalences (\%) of gastric ulcer $(G U)$, duodenal ulcer $(D U)$, total peptic ulcer $(P U)$, and deformed duodenal bulb $(D D B)$ found by endoscopy in 339 men and 280 women, aged 20-69 years. Calculated numbers $(X)$ of peptic ulcers for the respective total populations are presented in brackets (Sørreisa 1987)

\begin{tabular}{|c|c|c|c|c|c|c|c|c|c|c|c|c|}
\hline & \multicolumn{6}{|c|}{ Epigastric pain and/or heartburn } & \multicolumn{6}{|c|}{ No epigastric pain or heartburn } \\
\hline & \multicolumn{3}{|c|}{$\operatorname{Men}(n=169)$} & \multicolumn{3}{|c|}{ Women $(n=140)$} & \multicolumn{3}{|c|}{$\operatorname{Men}(n=170)$} & \multicolumn{3}{|c|}{ Women $(n=140)$} \\
\hline & No & $\%$ & $X$ & No & $\%$ & $X$ & No & $\%$ & $X$ & No & $\%$ & $X$ \\
\hline $\begin{array}{l}\text { GU } \\
\text { DU } \\
\text { PU } \\
\text { DDB }\end{array}$ & $\begin{array}{r}3 \\
3 \\
6 \\
10\end{array}$ & $\begin{array}{l}1.8 \\
1.8 \\
3.6 \\
5.9\end{array}$ & $\begin{array}{l}(4) \\
(4) \\
(8) \\
(14)\end{array}$ & $\begin{array}{l}2 \\
4 \\
6 \\
9\end{array}$ & $\begin{array}{l}1 \cdot 4 \\
2 \cdot 9 \\
4 \cdot 3 \\
6 \cdot 5\end{array}$ & $\begin{array}{l}(3) \\
(6) \\
(9) \\
(13)\end{array}$ & $\begin{array}{l}0 \\
1 \\
1 \\
4\end{array}$ & $\begin{array}{l}- \\
0.6 \\
0.6 \\
2.4\end{array}$ & $\begin{array}{l}(-) \\
(5) \\
(5) \\
(18)\end{array}$ & $\begin{array}{l}1 \\
1 \\
2 \\
6\end{array}$ & $\begin{array}{l}0.7 \\
0.7 \\
1.4 \\
4.7\end{array}$ & $\begin{array}{r}(6) \\
(6) \\
(10) \\
(35)\end{array}$ \\
\hline
\end{tabular}

Prevalences (\%) adjusted for age distribution in the local population.

distribution in the total population. Except for gastric ulcers in subjects with dyspepsia, we found higher point prevalences for peptic ulcers and deformed duodenal bulbs in women. The mean age of subjects with peptic ulcers was $45 \cdot 8$ years for men and $45 \cdot 6$ years for women. In the calculation of the number of expected peptic ulcers in the total population, we used the age adjusted prevalences for each ulcer localisation, total peptic ulcers, and deformed duodenal bulbs separately. Because of this the sum of the gastric and duodenal ulcers does not always correspond with the total number of peptic ulcers. Using age adjusted prevalences rather than the corresponding crude prevalences increased the number of peptic ulcers by one in both sexes and the number of deformed duodenal bulbs by one in men and two in women. The male:female ratio for calculated total peptic ulcer then became $0 \cdot 7: 1$, irrespective of whether deformed duodenal bulbs were included or not. The duodenal: gastric ulcer ratio was $2 \cdot 3: 1$ in men, and $1 \cdot 3: 1$ in women.

Table IV gives the overall prevalences in the total population. The $95 \%$ confidence limits, using the Poisson distribution, represent the estimated intervals of prevalence in any population comparable with that of Sørreisa. The prevalence of $7 \cdot 4 \%$ for peptic ulcer in men was significantly higher than that for women (4.6\%). When deformed duodenal bulbs were included in the peptic ulcer group, however, this difference disappeared, giving an overall prevalence of $10.5 \%$ in men and of $9.5 \%$ in women.

\section{Discussion}

This study was carried out in a well defined population and attracted a high response rate. The study also included blind endoscopy of all subjects with dyspepsia who agreed to the examination as well as of matched healthy controls. In addition we included a search for previously diagnosed peptic ulcers in the local medical records of all subjects who received a questionnaire. The study was designed to eliminate some of the major methodological problems inherent in most prevalence studies on peptic ulcer. To our knowledge, no previous study on peptic ulcer prevalence has used a similar design. Our main findings of a high overall prevalence, a sex ratio close to one, a somewhat unexpected duodenal:gastric ulcer ratio, and a high prevalence of asymptomatic ulcers may mainly be ascribed to our study design.
Lifetime prevalences for peptic ulcer in previous surveys vary from $5 \cdot 2$ to $9.0 \%$ in men and 1.9 to $6.0 \%$ in women. ${ }^{511}{ }^{16-19}$ Necropsy studies, on the other hand, have shown considerably higher prevalences, varying from 18.4 to $20.9 \%$ in men and from 9.5 to $14.7 \%$ in women. ${ }^{12} 20$ Unfortunately, the occurrence of peptic ulcer caused by terminal illnesses is unknown, and since most necropsy populations are highly selected, any comparison with prevalence studies on healthy subjects is questionable.

Our estimated overall prevalences of peptic ulcer disease of $10.5 \%$ in men and $9.5 \%$ in women are higher than those previously reported ' for men and even more so for women.

Most prevalence and incidence studies of peptic ulcer have been in patient populations where selection is biased by both the patient's and the doctor's decisions. Even in population based studies, ${ }^{15} 11$ the diagnostic procedures have mainly included subjects with severe symptoms, thereby excluding those with minor or no complaints. We have avoided these biases by offering endoscopy to all subjects with dyspepsia together with healthy matched control subjects.

Most surveys have reported that peptic ulcer disease is two to four times more frequent in men than in women, ${ }^{51121}$ but the male:female ratio varies both with age and ulcer location. It may thus approach a 1:1 ratio according to Kurata, ${ }^{4}$ and also to Doll and Banke in those above 55 years of age. ${ }^{11}$ In a follow up study of 174 patients with non-ulcer dyspepsia, Krag fround that $39 \%$ of the men and $42 \%$ of the women subsequently developed a peptic ulcer. ${ }^{22}$ The male:female ratio of $0 \cdot 7: 1$ in the estimated point prevalences of peptic ulcers contrasts with both the corresponding ratio of previously diagnosed peptic ulcers in this population and with those reported in other studies. ${ }^{51121}$ The number of peptic ulcers found by endoscopy was small, but the same sex distribution was found among the considerably larger number of deformed duodenal bulbs. These findings indicate that peptic ulcer has been underdiagnosed in women in our population, and this may also be the case in other studies on patient populations. This could partly be due to asymptomatic ulcers, but even among the subjects with dyspepsia, women had more peptic ulcers. The idea that peptic ulcer is mainly a male disease may have led to a higher diagnostic intensity in men.

In the USA and Europe, duodenal ulcer usually occurs at least twice as frequently as

TABLE IV Estimated ${ }^{\star}$ overall prevalences (and 95\% confidence intervals $\dagger$ of gastric ulcer, duodenal ulcer, and peptic ulcer exclusive and inclusive of deformed duodenal bulb $(D D B)$ in 1035 men and 992 women aged 20-69 years (Sørreisa 1987)

\begin{tabular}{|c|c|c|c|c|}
\hline & \multicolumn{2}{|c|}{$\operatorname{Men}(n=1035)$} & \multicolumn{2}{|c|}{ Women $(n=992)$} \\
\hline & $\%$ & CI & $\%$ & $\mathrm{CI}$ \\
\hline $\begin{array}{l}\text { Gastric ulcer } \\
\text { Duodenal ulcer } \\
\text { Peptic ulcer } \ddagger \\
\text { Peptic ulcer inclusive of }\end{array}$ & $\begin{array}{l}1 \cdot 7 \\
5 \cdot 2 \\
7 \cdot 4\end{array}$ & $\begin{array}{l}(1 \cdot 6-2 \cdot 1) \\
(4 \cdot 7-5 \cdot 8) \\
(6 \cdot 9-8 \cdot 2)\end{array}$ & $\begin{array}{l}2 \cdot 0 \\
2 \cdot 6 \\
4 \cdot 6\end{array}$ & $\begin{array}{l}(1 \cdot 5-2 \cdot 6) \\
(2 \cdot 0-3 \cdot 3) \\
(3 \cdot 8-5 \cdot 5)\end{array}$ \\
\hline DDB $\ddagger$ & $10 \cdot 5$ & $(9 \cdot 3-11 \cdot 9)$ & 9.5 & $(7 \cdot 9-11 \cdot 2)$ \\
\hline
\end{tabular}

*Combined figures from the endoscopy study and the record verification procedure.

+Based on Poisson distribution.

łIncluding ulcers with combined and unknown location. 
gastric ulcer. ${ }^{10182123}$ Previous studies in northern Norway have shown higher prevalences and incidences of gastric than duodenal ulcer. ${ }^{68}$ In southern Norway, on the other hand, Knutsen and Selvaag found a duodenal:gastric ulcer ratio of $1 \cdot 85: 1 .^{9}$ In Denmark, incidence rates in patient populations are some four times higher for duodenal $(0 \cdot 13 \%)$ than gastric ulcer $(0 \cdot 03 \%){ }^{10}$

One Norwegian study concluded that gastric ulcer relapses are often asymptomatic, ${ }^{12}$ but to our knowledge there are no published studies on prevalences of asymptomatic peptic ulcer. Point prevalences of $1 \cdot 0 \%$ for peptic ulcers and $3 \cdot 2 \%$ for deformed duodenal bulb among controls in this study indicate that asymptomatic peptic ulcers are common.

In our estimation of the overall prevalences we have treated those who did not respond to our questionnaire as control subjects. An alternative estimation, where the non-responders were given the point prevalence of subjects with dyspepsia, left the overall prevalence almost unchanged.

All but 12 primary health records of those who underwent endoscopy were found and examined. No information on previous peptic ulcer was found, corresponding with the answers in the questionnaire. This indicates that the peptic ulcers found by endoscopy were first time peptic ulcers.

Despite the comprehensive design of this study, we still cannot account for several potential methodological problems. The unknown rate of scars from previous peptic ulcers and the unknown duration and incidences of asymptomatic and barely symptomatic peptic ulcers represent our major sources of uncertainty. All of these areas of insufficient knowledge with their corresponding flaws in almost any study design probably lead to a considerable underestimation of the true prevalence of peptic ulcer.

In conclusion, we claim that asymptomatic peptic ulcers are quite common, and even that the high overall prevalences found in this study must be regarded as minimum figures. Finally, we question the current opinion on the sex ratio of peptic ulcer disease.

1 Weir RD, Backett EM. Studies of the epidemiology of peptic ulcer in a rural community: prevalence and natural history of dyspepsia and peptic ulcer. Gut 1968; 9: 75-83.

2 Langman MJS. Changing patterns in the epidemiology of peptic ulcer. Clin Gastroenterol 1973; 2: 219-26.

3 Sonnenberg A. Geographic and temporal variations in the occurrence of peptic ulcer disease. Scand $\mathcal{F}$ Gastroenterol occurrence of peptic ulcer
1985; 20 (suppl 110): 11-24.

4 Kurata JH, Haile BM, Elashoff JD. Sex differences in peptic ulcer disease. Gastroenterology 1985; 88: 96-100

5 Doll R, Jones FA, Buckatzsch MM. Occuptional factors in the aetiology of gastric and duodenal ulcers. Medical Research Council. Report no 276. London: MSO, 1951

6 Poppe E. Localization of peptic ulcer in a series of cases from Troms and Tromsø hospital, Norway. Tidsskr Nor Laegeforen 1945; 30: 1063-5.

7 Schanke $K$. The behavior of gastric and duodenal ulcer in a fishing district in the north of Norway. Studies on the frequency and localisation of gastroduodenal ulcer. Acta Chir Scand 1946; suppl 115: 94.

8 Østensen H, Gudmundsen TE, Bol\% KD, Burhol PG Bonnevie $O$. The incidence of gastric ulcer and duodenal ulcer in North Norway. A prospective epidemiological ulcer in North Norway. A prospective

9 Knutsen B, Selvaag O. The incidence of peptic ulcer. An investigation of the population of the town of Drammen. investigation of the population of
Acta Med Scand 1947; 196: 341-60.

10 Bonnevie O. Epidemiologiske studier af gastroduodenale ulcera's incidens, kombination og forlop. (SN), København, 1979.

11 Banke L. Ulcussykdommens epidemiologi. København Århus-Odense: F. A. D. L. s forlag, 1975.

12 Lindstrøm CG. Gastric and duodenal peptic ulcer disease in a well-defined population. Scand $\mathcal{F}$ Gastroenterol 1978; 13 : 139-43.

13 Jorde R, Bostad L, Burhol PG. Asymptomatic gastric ulcer: a follow-up study in patients with previous gastric ulcer disew-up study in patients

14 Fleiss JL. Statistical methods for rates and proportions. New York: Wiley-Interscience, 1973

15 Nie HH, Hull CH, Jenkins JG, Steinbrenner K, Bent DH SPSS. Statistical package for the social sciences. 2nd ed. New York: McGraw Hill Inc, 1975.

16 Jones FA. Social aspects of peptic ulcer. $\mathcal{F} R$ Inst Publ Health 1955; 18: 64-74

17 Almy TP. Prevalence and significance of digestive disease, a conference. Gastroenterology 1975; 68: 1351-71

18 Monson RR, MacMahon B. Peptic ulcer in Massachusetts physicians. N Engl f Med 1969; 28: 11-5.

19 Johnsen R, Straume B, Forde OH. Peptic ulcer and non-ulcer dyspepsia - a disease and a disorder. Scand F Prim Health Care 1988; 6: 239-43.

20 Watkinson $G$. The incidence of chronic peptic ulcer found at necropsy. Gut 1960; 1: 14-31.

21 Pulvertaft $\mathrm{CN}$. Peptic ulcer in town and country. Br $\mathcal{F}$ Prev Soc Med 1959; 13: 131-8.

$22 \mathrm{Krag}$ E. Pseudo-ulcer and true peptic ulcer. A clinical, radiographic and statistical follow-up study. Acta Med Scand 1965; 178: 713-28.

23 Kurata JH, Honda GD, Frankl H. Hospitalization and mortality rates for peptic ulcers: a comparison of a large HMO and US data. Gastroenterology 1982; 83: 1008-16. 